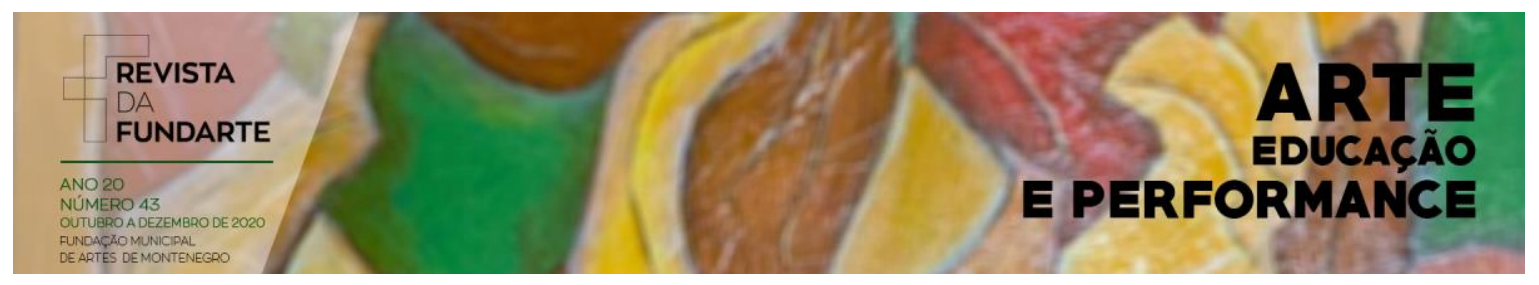

\title{
NARRATIVA BIOGRÁFICA: UM ENTENDIMENTO SOBRE A CONSTRUÇÃO DE DISCURSO NO FILME OLGA
}

\author{
Carine Luisa klein
}

DOI: http://dx.doi.org/10.19179/2F2319-0868/2F828 


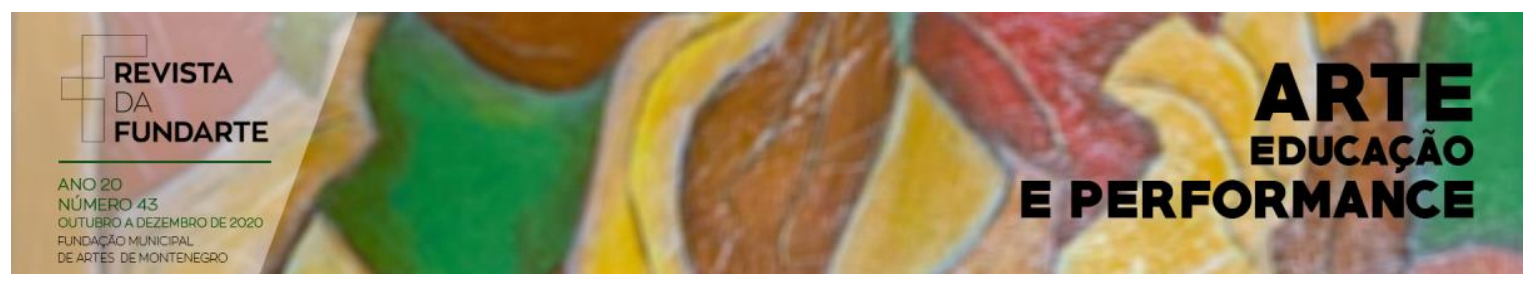

\title{
NARRATIVA BIOGRÁFICA: UM ENTENDIMENTO SOBRE A CONSTRUÇÃO DE DISCURSO NO FILME OLGA
}

Carine Luisa klein ${ }^{1}$

\begin{abstract}
Resumo: O presente artigo visa entender como se dá a construção narrativa biográfica, a partir das estruturas discursivas construídas na manifestação audiovisual. Tal concepção se orienta pela história biográfica de Olga Benário Prestes, uma jovem alemã que se torna comunista e sua militância é praticada, também, no Brasil. Neste estudo são apontados os modos narrativos da biografia fílmica, bem como a relevância na reconstrução de realidades contextuais tendo como ponto de partida o indivíduo biografado.
\end{abstract}

Palavras-chave: Biografia; Cinebiografia; Narrativa; Olga.

\section{BIOGRAPHICAL NARRATIVE: An UNDERSTANDING ABOUT THE CONSTRUCTION OF SPEECH IN THE FILM OLGA}

\begin{abstract}
The present article wants to understand how a biographical narrative is constructed, from the discursive structures in the audiovisual manifestation. This conception is guided by the biographical history of Olga Benário Prestes, a German girl who becomes a communist and her militancy is also practiced in Brazil. In this study are pointed out the narrative modes of the film biography and the relevance in the reconstruction contextual realities starting from a person.
\end{abstract}

Keywords: Biography; Film biography; Narrative; Olga.

\section{INTRODUÇÃO}

O propósito deste artigo é entender como se dá a construção narrativa de uma história de vida, partindo de uma compreensão histórica de biografia, indivíduo biografável e cinebiografia, tendo como fonte balizadora do estudo, o filme Olga (2014), dirigido por Jayme Monjardim, e adaptado do livro homônimo escrito por Fernando Morais (1994).

Com esta pesquisa, também, busca-se identificar e relacionar a História, a Comunicação e a Literatura dentro da narrativa ficcional, considerando - de antemão - a presença de elementos reais na construção narrativa da vida de Olga Benário Prestes.

\footnotetext{
1 Bacharel em Jornalismo; especialista em Gestão Cultural e mestrando em Processos em Manifestações Culturais. Atua no jornalimo de TV como apresentadora e repórter.
}

KLEIN, Carine Luisa. Narrativa biográfica: um entendimento sobre a construção de discurso no filme Olga. Revista da FUNDARTE. Montenegro, p.01-15, ano 20, ํㅡ 43, outubro/dezembro de 2020.

Disponível em: http://.seer.fundarte.rs.gov.br/index.php/revistadafundarte/index> 20 de dezembro de 2020. 


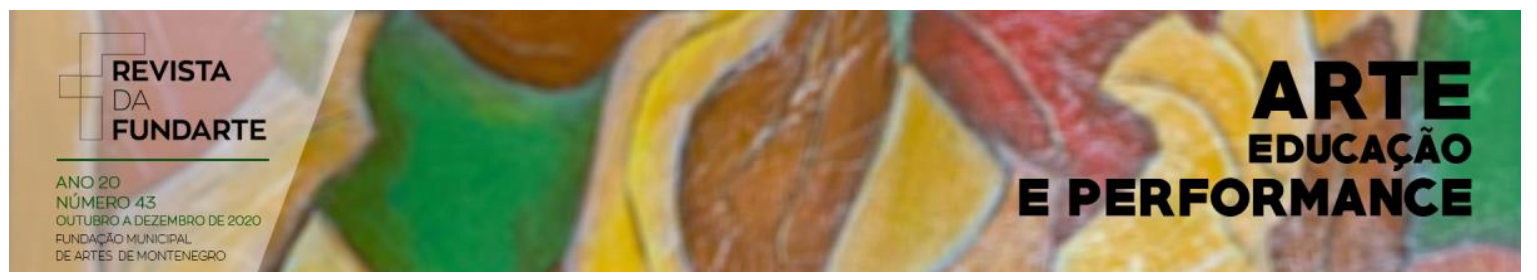

\section{BIOGRAFIA: CONTANDO A HISTÓRIA DE UM INDIVÍDUO}

A narrativa faz parte da história da humanidade, como aponta Barthes (1976), considerando que não há povo sem narrativa, que "(...) pode ser sustentada pela linguagem articulada, oral ou escrita, pela imagem, fixa ou móvel, pelo gesto ou pela mistura ordenada de todas estas substâncias" (BARTHES, 1976, p. 19).

Conforme Pereira (2000), o gênero biográfico surgiu propiciado pela expansão e afirmação dos direitos individuais, que era um ideário da Revolução Francesa. A biografia é a história de um indivíduo redigida por outro, ao mesmo tempo em que tem "(...) a preocupação de revelar não apenas a vida do sujeito, mas também a relação de suas ações com fatos históricos" (SCHEMES, SARAIVA, ARAÚJO, 2011, p. 131).

Entretanto, não há apenas um único tipo de biografia. Pereira (2000) explica que as possibilidades variam, desde situações em que as narrativas servem para ilustrar formas típicas de comportamento, até casos de uma trajetória de vida, sem fazer uso do contexto histórico.

Uma característica sobre biografia, relatada por Bourdieu (1998), é a apresentação oficial, como por exemplo, de dados pessoais. No caso do objeto de análise deste artigo, esses elementos são importantes - sobretudo - o nome próprio, ao passo de ser destaque como título da obra cinematográfica: Olga.

Por essa forma inteiramente singular de nominação que é o nome próprio, institui-se uma identidade social constante e durável, que garante a identidade do indivíduo biológico em todos os campos possíveis onde ele intervém como agente, isto é, em todas as suas histórias de vida possíveis. (BOURDIEU, 1998, p. 186, grifo do autor)

Portanto, para Bourdieu (1998, p. 187), o nome próprio é um identificador através dos tempos e dos espaços sociais; "(...) o fundamento da unidade de suas sucessivas manifestações, e da possibilidade socialmente reconhecida de totalizar essas manifestações em registros oficiais (...)". 2020. 


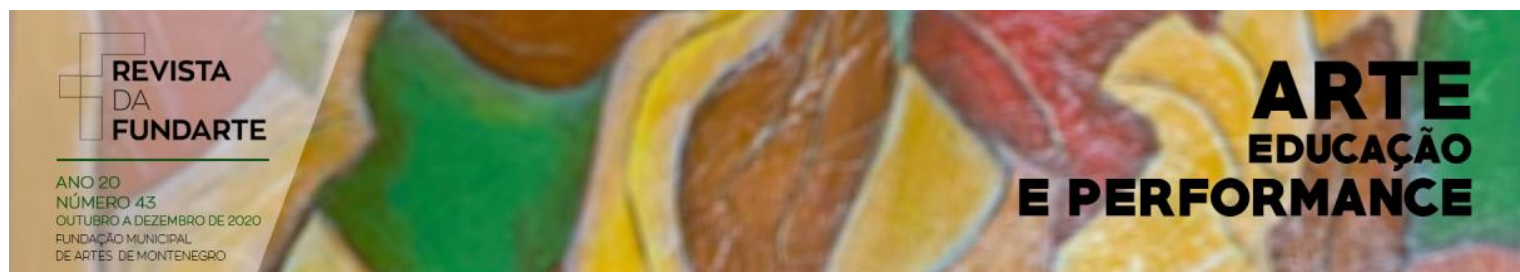

Ainda sobre esses dados oficiais, Borges (2005) aponta que biografias são construídas, balizadas por fontes documentais e entrevistas sobre o passado do sujeito biografado. Para Borges (2005), a narrativa sobre a vida de alguém é uma fonte de pesquisa sobre a época.

A biografia acompanha a revalorização da História Oral, como explica Pereira (2000). Por conta disso, faz uso de fontes, métodos, técnicas de pesquisa, assim como também os arquivos pessoais, que são preciosa fonte histórica. A autora acrescenta que "quando se trata de reconstituir a trajetória de alguém já falecido, temos de nos contentar com a documentação escrita e os depoentes que se encontram disponíveis, sem falar que nem sempre temos a sorte de nos depararmos com ricos arquivos pessoais" (PEREIRA, 2000, p. 118).

Situação pela qual o jornalista Fernando Morais passou, e relata no início de sua obra literária, sobre a vida de Olga Benário Prestes:

Logo que iniciei a investigação para escrever este livro, em 1982, percebi que as dificuldades para recompor o retrato de Olga seriam muito maiores do que supunha. No Brasil não havia praticamente nada sobre ela (...) Os poucos sobreviventes que testemunharam sua saga - na Alemanha e no Brasil - eram, no mínimo, octogenários, nem todos com memória ou condições de saúde para desenterrar detalhes de episódios acontecidos meio século antes. (MORAIS, 1994, p. 09).

Schmidt (2000) defende a ideia de que a busca pela informação sobre a vida de um sujeito a ser biografado deve ocorrer em vários cenários, ou seja,

[...] os biógrafos não devem se fixar na busca de um coerência linear e fechada para a vida de seus personagens, mas que precisam sim apreender facetas variadas de suas existências, transitando do social ao individual, do inconsciente ao consciente, do público ao privado, do familiar ao político, do pessoal ao profissional, e assim por diante, sem tentar reduzir todas os aspectos da biografia em um denominador comum. (SCHMIDT, 2000, p. 12)

Essa variedade pode ser percebida no filme Olga, pois a vida da personagem é apresentada sob o fio condutor da militância política, ao mesmo tempo, em que apresenta conflitos familiares e vida pessoal construída ao lado de Prestes.

KLEIN, Carine Luisa. Narrativa biográfica: um entendimento sobre a construção de discurso no filme Olga. Revista da FUNDARTE. Montenegro, p.01-15, ano 20, oㅜ 43, outubro/dezembro de 2020.

Disponível em: http://.seer.fundarte.rs.gov.br/index.php/revistadafundarte/index> 20 de dezembro de 2020. 


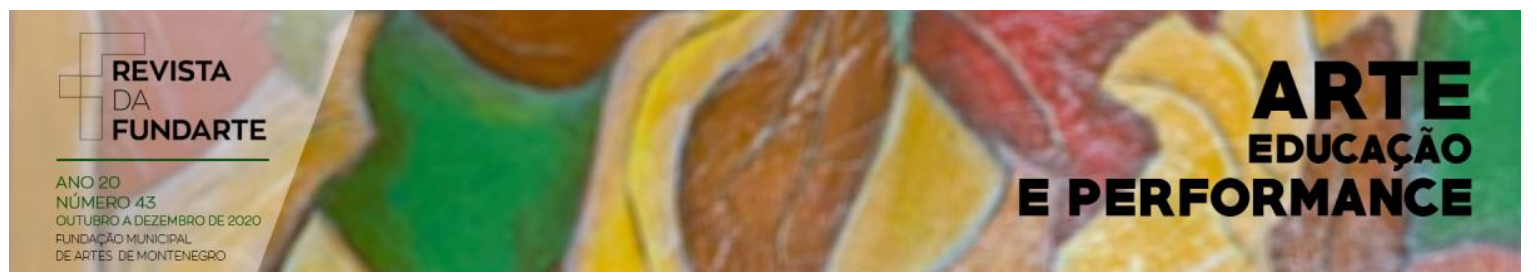

\section{O INDIVÍDUO BIOGRAFÁVEL}

Quem pode ser personagem de uma biografia? Schmidt (2012) relembra um pouco da história e de como os sujeitos se tornaram seres biografáveis. Em suma, a ideia da biografia era, a partir de um indivíduo, oferecer "(...) exemplos e contraexemplos de ação e de conduta que devem ser imitados ou refutados pelos homens do presente" (SCHMIDT,2012, p. 188). Assim, na Antiguidade, as biografias tinham, sobretudo, um objetivo moral, como contextualiza o autor.

Schmidt (2000) explica que os biógrafos tradicionais se voltavam àqueles a quem se atribuía o fazer história e, na atualidade, o interesse está em pessoas comuns.

Por muito tempo, a História só era considerada séria e confiável se relatasse as trajetórias de vida de personagens ilustres, aqueles que eram responsáveis por acontecimentos consagrados, como apontam Schemes, Saraiva e Araújo (2011). As autoras ainda revelam que

[...] muitos historiadores sentiam-se insatisfeitos com as limitações impostas pelas correntes historiográficas tradicionais, e romperam barreiras por elas impostas, dando forma a novas maneiras de expressar este passado e seus sujeitos, entre elas, a biografia. (SCHEMES, SARAIVA, ARAÚJO, 2011, p. 129).

Mesmo se tratando de um indivíduo real, na biografia ele se torna personagem, pois sua vida passa ser contada por meio de cenas retratadas e que a cada momento revelam um pouco mais sobre a personalidade da personagem. Bourneuf e Ouellet (1976) explicam que na história, o sujeito biografado é mostrado a partir das relações com as outras personagens, "descobrirá a cada uma, um aspecto do seu ser que só o contacto numa dada situação podia pôr em relevo" (BOURNEUF, OUELLET, 1976, p. 200). Essa rede de relações, também, se dá com os ambientes e os objetos pelos quais o indivíduo passa.

O protagonista de uma história é responsável pelos conflitos condutores da narrativa, conforme Bourneuf e Ouellet (1976). A exemplo de Olga, todos os conflitos Olga. Revista da FUNDARTE. Montenegro, p.01-15, ano 20, № 43, outubro/dezembro de 2020.

Disponível em: http://.seer.fundarte.rs.gov.br/index.php/revistadafundarte/index> 20 de dezembro de 2020. 


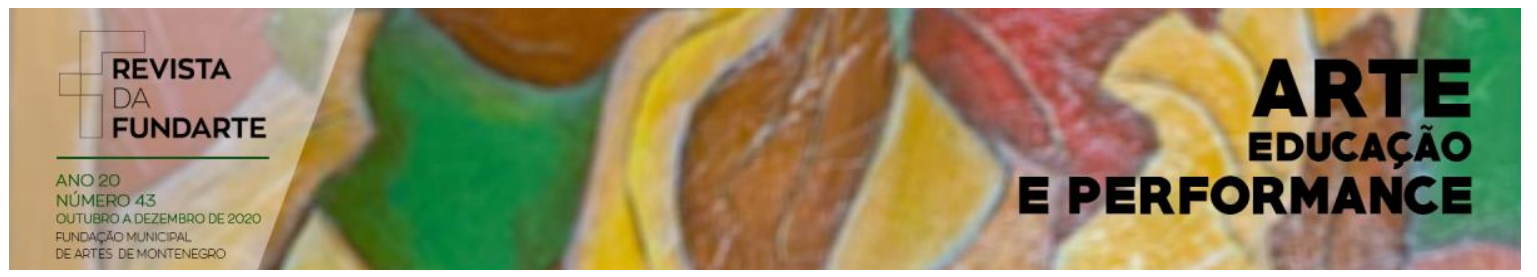

narrados perpassam pela vida da personagem-título, considerando e enaltecendo a sua importância na biografia.

[...] a vida de Olga Benário Prestes, uma história que me fascina e atormenta desde a adolescência, quando ouvia meu pai referir-se a Filinto Müller como o homem que tinha dado a Hitler, "de presente", a mulher de Luís Carlos Prestes, uma judia comunista que estava grávida de sete meses. Perseguido por essa imagem, decidi que algum dia escreveria sobre Olga [...]. (MORAIS, 1994, p. 09).

Assim, Fernando Morais (1994) revela as suas motivações para escrever a biografia de Olga, que pode ser interpretado por um desejo pessoal de uma história ouvida que o marcou profundamente. Desta forma, o jornalista e escritor tornou Olga um ser biografável.

\section{CINEBIOGRAFIA: REALIDADE E FICÇÃO}

Antes de abordar mais sobre a cinebiografia, far-se-á uma breve introdução sobre filmes documentários e ficcionais. Nichols (2005) afirma que não é fácil definir o que é um documentário, pois tal conceito não cabe em uma explicação simplória. Logo,

se o documentário fosse uma reprodução da realidade, esses problemas seriam bem menos graves. Teríamos simplesmente a réplica ou cópia de algo já existente. Mas ele não é uma reprodução da realidade, é uma representação do mundo em que vivemos. (NICHOLS, 2005, p. 47, grifos do autor).

Ou seja, o filme documental representa uma determina visão do mundo, como reforça o autor. O mesmo entendimento é apresentado por Ramos (2000, p. 05), ao afirmar que, no documentário, um dos conceitos centrais, diz respeito a um discurso fílmico "[...] carregado de enunciados que possuem a característica de serem asserções, ou afirmações sobre a realidade". 2020. 


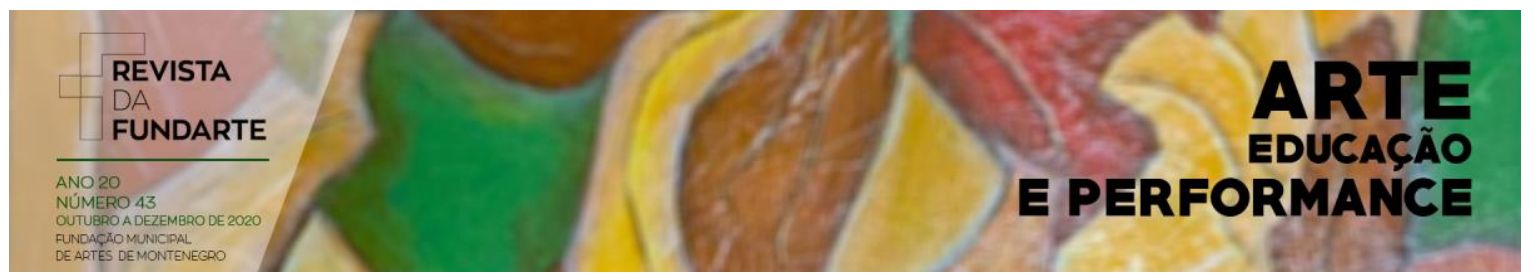

Já os filmes de ficção, não têm o compromisso com a narrativa da realidade objetiva. Contudo, ao assistir um filme, as emoções e sensações sentidas criam um "efeito de realidade", como explica Napolitano (2009, p. 11): "Essa característica, que é do cinema em si, se vê potencializada pela capacidade técnica cinematográfica atual, sobretudo a norte-americana, de criar uma encenação tão realista que nos transporta para o mundo projetado nas telas [...]".

Sendo assim, definir o gênero ficcional é, também, uma tarefa complexa, devido à sua amplitude. Segundo Lopes (2000, p. 23, grifos da autora)

\begin{abstract}
de um ponto de vista geral, a explicação do conceito de ficção encontrada em textos de estudiosos do assuntos, manuais, dicionários e enciclopédias se concentra, basicamente, nestas definições: fingimento, farsa, modelagem, imaginação, representação e invenção. "Além das referidas acepções, encontramos também a palavra "ficção" com o sentido de gênero literário, mais especificamente, designando os textos de prosa".
\end{abstract}

Considerando as explanações anteriores, acresce-se a afirmativa de Napolitano (2009), que todo filme é resultado de um conjunto de seleções, escolhas, recortes e perspectivas. Entretanto, o autor complementa que [...] "todo filme documental não é a representação direta da realidade, e que todo filme ficcional não está desligado da sociedade que o produziu" (NAPOLITANO, 2009, p. 12).

Portanto, o conteúdo apresentado nas narrativas documentais é composto por elementos não somente históricos. Há um acréscimo de imaginação, invenção e criação do roteirista; preenchendo lacunas que, por vezes a história não preencheu, ou compondo a história de um modo mais atrativo - e de narrativa conhecida - aos espectadores. Aqui, fazendo esse entendimento, com base no artigo de Schemes, Saraiva, e Araújo (2011).

Consoante a essa ideia, Levi (1998) relata que ao se construir a história de um sujeito, há informações sobre os fatos e não sobre as questões mais cotidianas, como dúvidas - por exemplo. Isso porque "as fontes de que dispomos não nos informam acerca dos processos de tomada de decisões, mas somente dos resultados destas, ou seja, acerca dos atos. Essa falta de neutralidade da Olga. Revista da FUNDARTE. Montenegro, p.01-15, ano 20, no 43, outubro/dezembro de 2020.

Disponível em: http://.seer.fundarte.rs.gov.br/index.php/revistadafundarte/index> 20 de dezembro de 2020. 


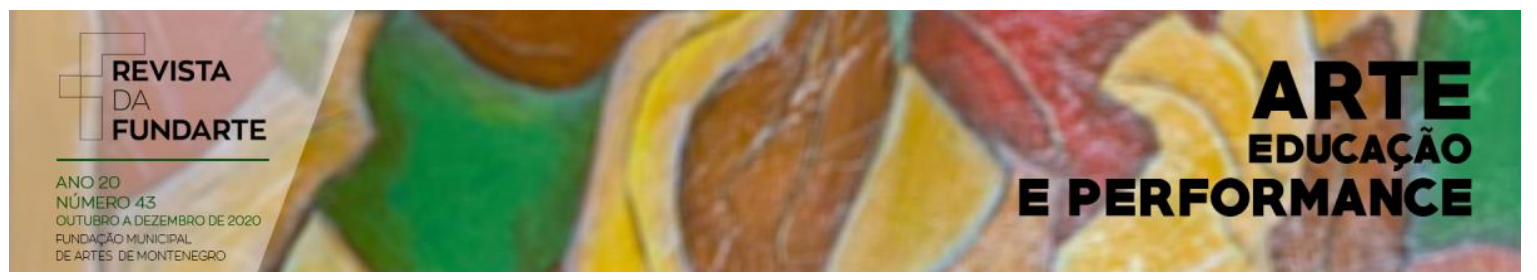

documentação leva muitas vezes a explicação monocausas e lineares” (LEVI, 1998, p.173-4).

Forster (1976) aborda que os historiadores tratam das ações e do caráter dos homens e fazem deduções dentro do que descobriram, ou seja, só podem afirmar o que lhe são mostrados. No entanto, os romancistas não têm essa preocupação e fazem deduções além dos vestígios apresentados. Forster (1976, p. 35) explica: “a vida oculta é, por definição, velada e, quando se mostra através de sinais exteriores, não é mais oculta, já entra no domínio da ação. E a função do romancista é revelar essa vida oculta na sua fonte".

Por muito tempo, os historiadores tentaram banir a ficção das biografias, como explana Schmidt (2000, p. 15, grifo do autor), que acrescenta que "(...) historiadores e jornalistas, por dever do ofício, têm um maior compromisso com o 'mundo real', enquanto que cineastas e literatos podem contar com uma margem muito mais significativa de invenção".

Isso quer dizer que na história de Olga há muitos fatos verdadeiros/históricos, no entanto, há construção ficcional paralela, onde não se sabe o que foi inventado e o que é - de fato - informação real. Assim, criando a cruza entre realidade e ficção, que tanto caracteriza as biografias.

Um modelo de construção das histórias de vida, é a biografia cinematográfica. Para Negrini e Gutfreind (2019, p. 222), "as cinebiografias são observadas como vetores de produções históricas, pois são potências de ressignificação crítica da história".

Levi (1998) traz uma passagem de Raymond Queneau para afirmar que houve uma época em que era possível contar a história de alguém sem fazer relação com o contexto histórico. Anos depois, isso já não é mais uma verdade inquestionável e, atualmente, a biografia é utilizada “(...) para sublinhar a irredutibilidade dos indivíduos e de seus comportamentos a sistemas normativos gerais, levando em consideração a experiência vivida" (LEVI, 1998, 167). Esse é o Olga. Revista da FUNDARTE. Montenegro, p.01-15, ano 20, no 43, outubro/dezembro de 2020.

Disponível em: http://.seer.fundarte.rs.gov.br/index.php/revistadafundarte/index> 20 de dezembro de 2020. 


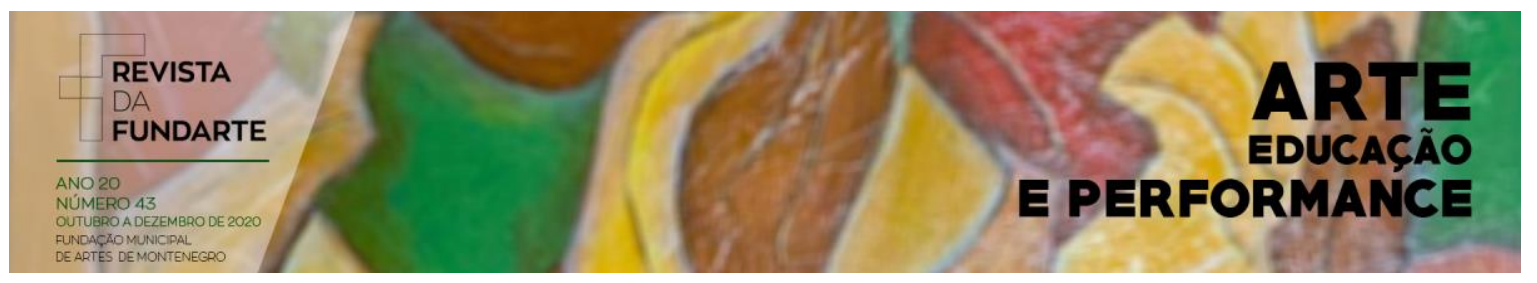

caso da cinebiografia Olga, cuja vida pessoal da personagem é apresentada juntamente com o contexto sócio-histórico-cultural da época.

O autor, ainda, complementa expondo que a biografia “(...) é vista como o terreno ideal para provar a validade de hipóteses científicas concernentes às práticas e ao funcionamento efetivo das leis e das regras sociais" (LEVI, 1998, 167).

Já Schmidt (2000, p. 07) acredita que as referências históricas nas cinebiografias, de um modo geral, "(...) servem mais como uma ambientação para as ações e sensações dos personagens, conferindo verossimilhança à narrativa".

As novas narrativas biográficas resgatam as diferentes facetas das personagens, como revela Schmidt (2000), e não apenas a vida pública e seus feitos notáveis, como ocorriam nas biografias tradicionais. Como consequência, "(...) emergem nestes textos, entre outros aspectos, os sentimentos, o inconsciente, a cultura, a dimensão privada e o cotidiano" (SCHMIDT, 2000, p. 11)

No caso de Olga, o contexto político-econômico se mistura à vida da personagem, uma vez que a trajetória de vida dela é narrada pelos acontecimentos e lutas da militância política. Assim como a vida pessoal da personagem-título, a relação com a família, com o marido e a separação da filha são exemplos das emoções e dos sentimentos retratados da personagem na história biografada.

\section{A NARRATIVA DE OLGA}

O filme conta a história de vida de Olga Benário, uma jovem alemã que se torna militante comunista. Olga, após retirar seu namorado, Otto Braun, da cadeia, precisa fugir para a União Soviética. No novo local, ela recebe treinamento de guerrilha. Olga se destaca no Partido Comunista e, por conta disso, é encarregada de acompanhar Luís Carlos Prestes, que é brasileiro, em seu retorno ao país. Enquanto planejam a Intentona Comunista ${ }^{2}$ contra o Presidente Getúlio Vargas, os

\footnotetext{
2 Nome dado à tentativa de golpe contra o governo Vargas, em 1935.
}

KLEIN, Carine Luisa. Narrativa biográfica: um entendimento sobre a construção de discurso no filme Olga. Revista da FUNDARTE. Montenegro, p.01-15, ano 20, nº 43, outubro/dezembro de 2020.

Disponível em: http://.seer.fundarte.rs.gov.br/index.php/revistadafundarte/index> 20 de dezembro de 2020. 


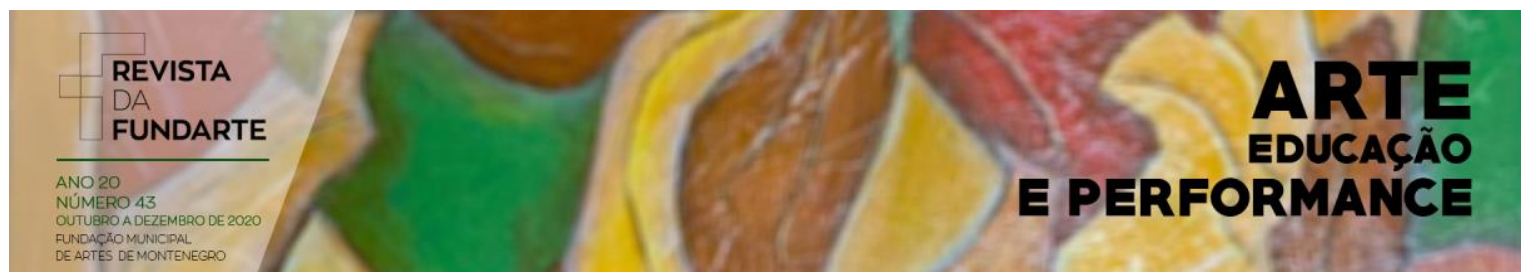

dois acabam se envolvendo em uma relação pessoal, ultrapassando a parceria política.

Quando o movimento revolucionário, do qual fazem parte Olga e Prestes, é derrotado, ambos são presos. Em meio a notícias de que ela seria deportada, Olga anuncia sua gravidez, pedindo - assim - asilo político.

Neste período, o governo brasileiro de Vargas simpatizava com a ditadura de Adolf Hitler e, portanto, decide deportá-la. Na prisão alemã, Olga dá à luz à filha, batizada de Anita Leocádia, homenageando a mãe de Luís Carlos Prestes. Após o período de amamentação, a menina é separada da mãe e levada para ser criada pela avó paterna.

Olga permanece presa por muitos anos e é morta na câmara de gás. No entanto, antes disso, ela escreve uma carta de despedida à filha e ao marido. Estes recebem a mensagem anos depois da morte de Olga Benário - porém, ainda, sendo uma comovente despedida.

Esse é um resumo da biografia de Olga, apresentada no filme homônimo, de 2004, dirigido por Jayme Monjardim. A história original foi escrita pelo jornalista Fernando Morais, em 1994, e - então - dez anos depois foi narrada no cinema. Uma curiosidade sobre biografias escritas por jornalistas é apresentada por Schemes, Saraiva e Araújo (2011, p. 136), ao explicarem que o comunicador tem como tarefa apresentar a vida detalhada do indivíduo biografado para os leitores.

\footnotetext{
Para atender a esse objetivo, o escritor deve apresentar aos leitores os fatos que marcaram a vida do objeto da biografia, bem como aquelas pessoas que compartilharam situações, vivências. Nessa apresentação, está em jogo menos a verdade do que a verossimilhança, mas, para que ela se efetive, é necessário que o escritor dê coerência aos fatos vivenciados pelo biografado. Muitas vezes, os acontecimentos relatados pelos próprios indivíduos parecem não ter conexão, por isso cabe ao jornalista interrelacioná-los, pois, caso contrário, o leitor não compreenderá a exposição dos eventos. (SCHEMES, SARAIVA, ARAÚJO, 2011, p. 136).
}

Para Pierre Bourdieu (1998), na narrativa biográfica, a vida é retratada como uma história organizada, tendo um deslocamento unidirecional. Olga. Revista da FUNDARTE. Montenegro, p.01-15, ano 20, no 43, outubro/dezembro de 2020.

Disponível em: http://.seer.fundarte.rs.gov.br/index.php/revistadafundarte/index $>20$ de dezembro de 2020. 


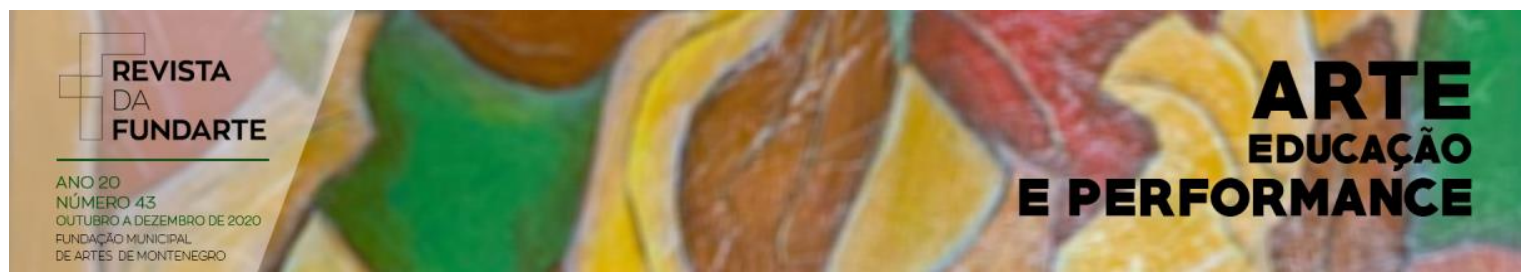

No filme Olga, por exemplo, a narrativa é contada a partir de lembranças da personagem principal. O momento presente do filme é o quando Olga está presa e, já separada da filha. Entretanto, a partir das lembranças da personagem, a história é contada de modo cronológico, iniciando com uma passagem da adolescência dela. Essa lógica temporal, de acordo com Bourdieu (1998), é resultado de uma tradição literária. Isso porque, a vida acontece em uma sequência lógica, pois o real é descontínuo.

Para Barthes (1976) a análise estrutural de uma narrativa deve começar pela própria linguística. E é a linguagem da cinebiografia Olga que provoca uma intimidade entre espectador e personagem, a partir da exposição da vida privada da protagonista. Negrini e Gutfreind (2019) afirmam que deste modo, o filme de Jayme Monjardim relaciona diferentes temporalidades, mostrando as técnicas de coerção e a restrição de direitos fundamentais,

há, portanto, em Olga, um diálogo com o contexto democrático que se apresenta pelas reminiscências do passado ditatorial. [...] Assim, a narrativa cria uma simultaneidade que dá a ver as experiências discricionárias do Estado brasileiro como afetividades que permeiam o social. (NEGRINI, GUTFREIND, 2019, p. 227, grifo dos autores)

Barthes (1976, p. 51) corrobora com o entendimento anterior, ao assegurar que "o nível narracional é, pois, ocupado pelos signos da narratividade, o conjunto dos operadores que reintegram funções e ações na comunicação narrativa, articulada sobre seu doador e seu destinatário".

Por fim, Schemes, Saraiva e Araújo (2011) destacam que o processo discursivo contribui para enfatizar as diferenças entre os campos da Literatura, da História e do Jornalismo, nos quais podem ser lidos como biografias literárias, contexto histórico e veracidade e verossimilhança. Dessa forma, as autoras colocam que as biografias promovem uma reflexão sobre esses campos e, ainda, enriquecem com a análise de suas manifestações. Olga. Revista da FUNDARTE. Montenegro, p.01-15, ano 20, № 43, outubro/dezembro de 2020.

Disponível em: http://.seer.fundarte.rs.gov.br/index.php/revistadafundarte/index $>20$ de dezembro de 2020. 


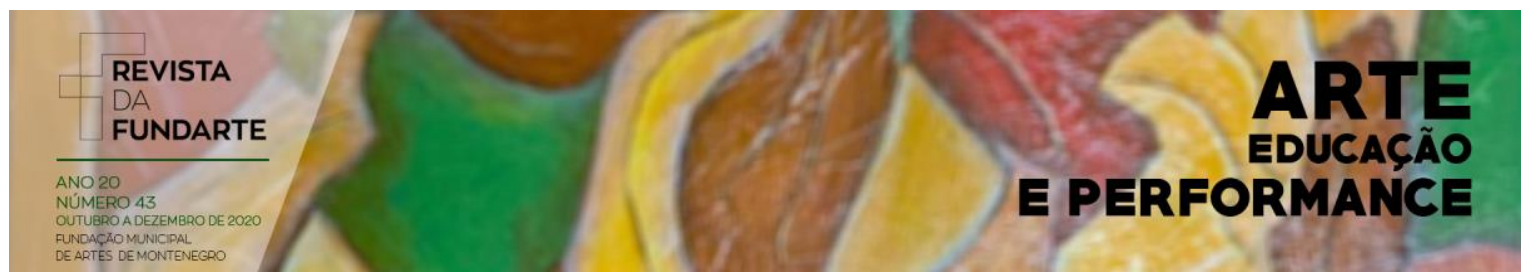

Portanto, a partir de Olga, o espectador pode ter um contato com a história política do Brasil e da Alemanha, quando conhece a vida narrada de Olga Benário Prestes.

\section{CONSIDERAÇÕES FINAIS}

Ao longo deste artigo, foram apresentados três motes que conduziram este estudo: a biografia, o indivíduo biografável e a cinebiografia; todos dialogando com a história de vida de Olga Benário Prestes, a partir da narrativa apresentada no filme Olga, de Jayme Monjardim (2004).

Ainda, buscou-se compreender de que forma a História está presente na construção fílmica, bem como identificar os elementos comunicacionais (já que é uma obra construída sobre contextos sócio-histórico-culturais) e literários (levando em conta que se trata de uma obra com elementos ficcionais).

A História é um elemento de destaque em Olga, pois a narrativa de vida da personagem-título é guiada pela sua militância política. Como explicado anteriormente, Olga Benário Prestes foi uma jovem alemã que se tornou militante comunista. Em sua luta, recebeu treinamento de guerrilha e se destacou dentro do Partido Comunista. Suas ações de bravura a colocaram em um papel de destaque junto à Intentona, cujo objetivo era derrubar o Governo Vargas, em 1935.

A história de vida da personagem é apresentada sob o fio condutor político, as decisões tomadas por Olga ao longo de sua existência foram influenciadas pelos desejos e valores políticos. Deste modo, o discurso narrativo de Olga tem importância para a História, pois a vida da personagem é narrada a partir desta perspectiva.

Sob esse aspecto, também, é possível identificar a presença da Comunicação. O intuito deste campo é informar o público sobre fatos verídicos para que eles possam tirar suas próprias conclusões. Considerando isso, percebe-se que quando uma narrativa apresenta elementos baseados em fatos históricos, ela está 2020. 


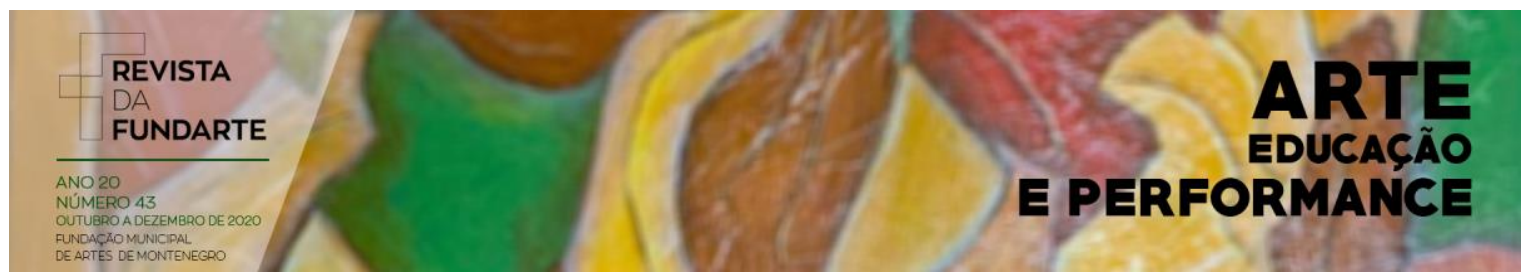

informando o público sobre acontecimentos reais, assim, trabalhando com a comunicação.

Os vestígios reais da história podem ser confrontados e comprovados, por isso é fundamental ter um cuidado minucioso sobre o relato de tais acontecimentos. Alguns exemplos sobre a veracidade apresentada em Olga, pode ser confirmada na presença de nomes, datas, acordos pessoais e marcos - a exemplo da Intentona.

No filme, também, é possível encontrar a presença da Literatura, tendo por base o fato simplório de se tratar de uma obra ficcional, neste caso, misturada à realidade.

Elementos da Literatura se apresentam no discurso narrativo com as características da construção fílmica, a composição de diálogos e a construção da personalidade dos sujeitos. O discurso construído com base na cronologia, como apresentada por Bourdieu (1998), é uma característica relacionada à Literatura; bem como a construção linguística, ressaltada por Barthes (1976).

O discurso que compõe a cinebiografia foi construído a partir de uma narrativa já existente, que era a escrita do livro Olga. Os elementos supracitados podem ser entendidos como ficcionais, pois para a sua elaboração requerem a imaginação do escritor, uma vez que não é possível identificar as reações e os sentimentos das pessoas, a partir de registros puramente dos fatos.

Portanto, para concluir, entende-se que os pontos aqui abordados possibilitam a ampliação do debate sobre biografias, indivíduos biografáveis e cinebiografias. Em paralelo, também, convidam a visualizar a interdisciplinaridade com diversas outras áreas do conhecimento e do entretenimento.

Para este estudo, focou-se na inter-relação da História, da Comunicação e da Literatura, para exemplificar essa pluralidade existente no discurso narrativo, e se observou isso a partir da história de Olga.

Da mesma forma que o debate sobre o assunto não se finda com o término deste artigo, as possibilidades de análise, também, não. Olga é, apenas, um exemplo de como as áreas estão interligadas e de como elas podem ser 2020. 


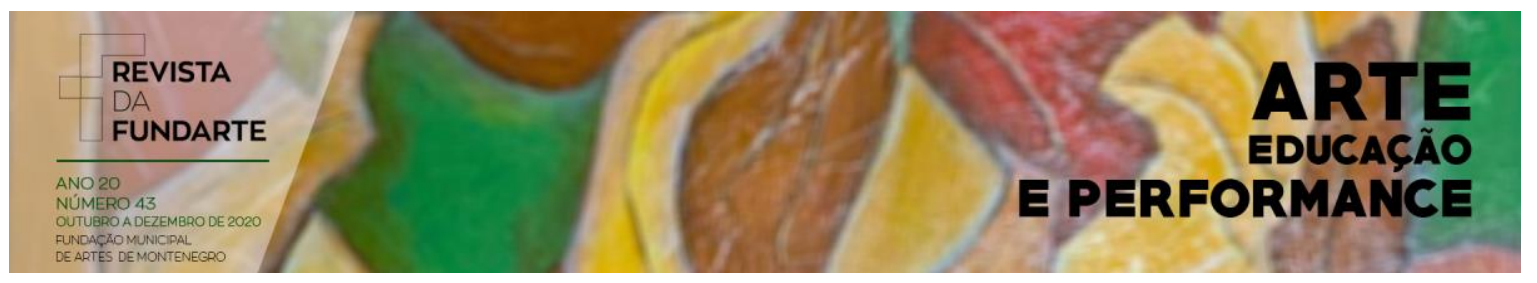

apresentadas ao público - certamente, inúmeros outros casos podem servir de inspiração para pesquisas semelhantes, pois como afirma Schmidt (2000, p. 18), “(...) não é fácil a tarefa de 'contar uma vida', seja com luz ou papel, realidade ou imaginação...".

\section{Referências:}

BARTHES, Roland. Introdução à análise estrutural da narrativa. In: BARTHES, Roland et al. Análise estrutural da narrativa. 4. ed. Petrópolis : Vozes, 1976, p. 1960.

BILL, Nichols. Introdução ao documentário - 3. ed. Tradução Mônica Saddy Martins. Campinas, SP : Papinus, 2005.

BORGES, Vavy Pacheco. Grandezas e misérias da biografia. In: PINSKI, Carla B. (org.). Fontes históricas. São Paulo: Ed. Contexto, 2005, p. 211.

BOURDIEU, Pierre. A ilusão biográfica. In: AMADO, Janaína. FERREIRA, Marieta de Moraes (org.). Usos e Abusos da História Oral - 2 ed. Rio de Janeiro :Editora da Fundação Getúlio Vargas, 1998, p. 183-91.

BOURNEUF, Roland. OUELLET, Réal. As personagens. In: O universo do romance. Coimbra : Almedina, 1976, p. 199-279.

FORSTER, Edward. As pessoas. In: Aspectos do romance. Rio de Janeiro : Editora Globo, 2005.

LEVI, Giovanni. Usos da biografia. In: AMADO, Janaína. FERREIRA, Marieta de Moraes (orgs.). Usos e abusos da história oral - 2. Ed. Rio de Janeiro : Editora da Fundação Getúlio Vargas, 1998, p. 167-182.

LOPES, Emília Mendes. O discurso ficcional: uma tentativa de definição. Disponível em: $<$ https://repositorio.ufmg.br/bitstream/1843/ARCO7FFQMK/1/emilia_mlopes_diss.pdf>. Acesso em: 25 Mar. 2020.

MORAIS, Fernando. Olga. - 17.ed. São Paulo : Companhia das Letras, 1994.

NAPOLITANO, Marcos. Cinema: a experiência cultural e escolar. In: Caderno de cinema do professor: dois / Secretaria da Educação, Fundação para o 2020. 


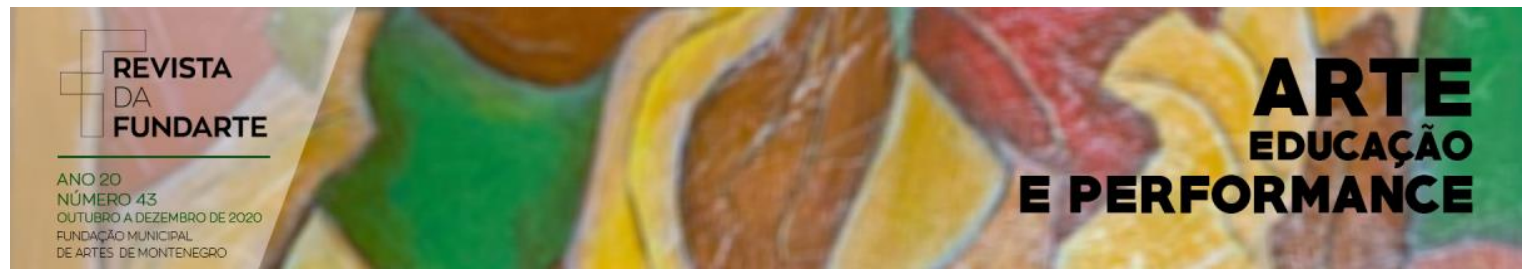

Desenvolvimento da Educação; organização, Devanil Tozzi ... [e outros]. - São Paulo : FDE, 2009. p. 10-31.

NEGRINI, Márcio Zanetti. GUTFREIND, Cristiane Freitas. Cinebiografias ficcionais e a representação da Era Vargas na contemporaneidade. In: AMINUS - Revista Interamericana de Comunicação Midiática, Santa Maria, v. 18, n. 36, 2019, p. 220 35.

PEREIRA, Lígia Maria Leite. Algumas reflexões sobre histórias de vida, biografias e autobiografias. In: História Oral: Revista da Associação Brasileira de História Oral, 3, São Paulo: ABHO, 2000, p.117-27.

RAMOS, Fernão Pessoa. O que é documentário? Disponível em: <http://ceangher.com.br/wp-content/uploads/2017/10/pessoa-fernao-ramos-o-quedocumentario.pdf>. Acesso em: 25 Mar. 2020.

SCHEMES, Claudia. SARAIVA, Juracy I. A.; ARAÚJO, Denise C. Memória e liminaridades entre discursos biográficos da História, do Jornalismo e da Literatura. In: Cadernos de Pesquisa Interdisciplinar em Ciências Humanas. Florianópolis, v. 12 , n. 100 , p. $126-158$, jan/jul 2011

SCHMIDT, Benito Bisso. Luz e papel, realidade e imaginação: as biografias na história, no jornalismo, na literatura e no cinema. In: SCHMIDT, Benito Bisso (org.). O Biográfico. Santa Cruz do Sul : UDUNISC, 2000, p. 49-70.

- História e biografia. In: Novos domínios da História. Rio de Janeiro: Elsevier, 2012, p. 187-205.

\section{Filmografia}

OLGA. Direção: Jayme Monjardim, 2004. Arquivo digital. 141 min. Olga. Revista da FUNDARTE. Montenegro, p.01-15, ano 20, № 43, outubro/dezembro de 2020.

Disponível em: http://.seer.fundarte.rs.gov.br/index.php/revistadafundarte/index $>20$ de dezembro de 2020. 